\title{
Investigating the Perspectives of Social Value for a UK Flood Alleviation Scheme
}

\author{
By Sarah Louise Fitton ${ }^{*}$ \\ Alice Moncaster \\ Peter Guthrie
}

The argument presented in this paper calls for an approach to flood infrastructure that considers not only the need for a technical perspective in design and construction but also a social perspective. As a result of climate change and changing weather patterns, it is predicted that more intense rainfall will be experienced, as well as rising sea levels, resulting in a greater number of people across the world becoming vulnerable to flood events. The need for flood alleviation infrastructure is therefore highly likely to increase. However industry professionals responsible for design and construction have often neglected to see flooding as a social problem; consequently they focus only on the technical and costeffective, rather than the social end user orientated, aspects of their design solutions. This paper presents the preliminary findings from research that seeks to understand how the social value of flood alleviation schemes is interpreted and discussed. The results are derived from an examination of the Didsbury Flood Storage Basin Improvements scheme between April and August 2013 in Manchester, UK. A series of semi-structured interviews were conducted with both the community and those responsible for the design, delivery and construction of the scheme. The findings presented demonstrate how social value is articulated by both groups, and where a difference in interpretation and perspectives exists. These findings reinforce the argument that adopting a socially, as well as technically, considerate approach for future flood infrastructure design and construction is a necessity, as more communities around the world are exposed to the very real risk of flood events.

${ }^{*}$ PhD Student, University of Cambridge, UK.

${ }^{\dagger}$ Lecturer, University of Cambridge, UK.

${ }^{\star}$ Professor, University of Cambridge, UK. 


\section{Introduction}

The flood events experienced in areas of England during the winter months of late 2013 and early 2014 highlighted the vulnerability of an increasing number of people to the impacts of flooding. Within Europe, the frequency and intensity of heavy rainfall events has likely increased over the years and will continue to do so should current patterns in climate change persist (IPCC, 2013; Johannessen and Hahn, 2013; Tripathi et al., 2014). Sea levels are also rising and are likely to continue if current trends provide an indication of future trends (IPCC, 2013). The changes in weather patterns and rising sea levels result in a greater number of people within England at risk from flooding. The UK Government predicted that in 2013, approximately 5 million properties were at risk of varying degrees of flooding (HM Treasury, 2013). Should current weather patterns continue, properties facing significant flood risk could increase by 210,00 from 560,00 to 770,000 and even reach 1.3 million by 2050 (HM Treasury, 2013). This has been reflected in record Government investments in the area of flood protection as set out in the National Infrastructure Plan 2013 to provide protection to the people who are most vulnerable (HM Treasury, 2013). However, flood alleviation design and the infrastructure sector as a whole, has been strongly driven by economic and, to a lesser extent environmental considerations, which subsequently steer the design, delivery and construction (Cruz et al., 2009; Germond - Duret, 2012; Penning-Roswell and Pardow, 2012; Simm, 2012). Flooding is also a social problem and flood alleviation schemes are designed and constructed to protect people. However, the problem remains that if flood alleviation design is focussed upon economic and environmental drivers, it is not possible to ensure that future schemes are designed with the consideration of the people it is intended to protect.

The purpose of this paper is to present the preliminary findings of the research seeking to understand how the social value of a flood alleviation schemes is interpreted and discussed by both the local community and those responsible for the design, delivery and construction. The paper argues that by developing an understanding of the concept of social value in the context of the flood alleviation scheme, it may be possible to apply this method and the derived knowledge to begin to integrate a socially considered approach into decision-making on future flood alleviation schemes.

The paper is structured as follows: the next section provides background information concerning the research problem; Section 3 describes the methodological approach adopted for the research; Section 4 describes the preliminary results and discussion, while Section 5 presents the concluding remarks. 


\section{Background and Identification of the Research Gap}

\section{Current Perspectives on Infrastructure Design, Delivery and Construction}

The impacts of flooding have social consequences and there are social, economic and environmental drivers for the construction of flood alleviation schemes (Penning-Roswell and Pardow, 2012). However, current practice concerning flood alleviation design and construction, and indeed the infrastructure sector on the whole, focusses on the economic and environmental drivers more than the social (Cruz et al., 2009; Penning-Roswell and Pardow, 2012). Markard (2011) identifies a number of different perspectives from which infrastructure has been examined. This includes aspects such as the technical details of the physical structure, governance, marketing and financing mechanisms and operation and maintenance. However, development of the Large Technical Systems approach (LTS) in the 1980 's sought to incorporate a social perspective by examining infrastructure through a socio-technical lens (Geels, 2007; Hughes, 1983; Van der Vleuten, 2004). Jonsson has built upon this approach, seeking to examine and understand infrastructure from the perspective of the services created and the relationship with society (Jonsson, 2000; 2005). This approach has been based upon the fundamental needs that the services satisfy for society. Nevertheless, this still remains an under researched area and an area that is not significantly considered in current industry practice.

\section{Community Experiences}

Society experiences infrastructure in many different, complex ways (Marshall, 2012; Star, 1999) and this contributes to the fact that the social perspective is not more explicitly considered in current practice. Boztepe (2007) and Sandstrom et al. (2008) explain that the point at which society identifies any value in infrastructure is at the point of contact with the service created. This indicates that the experience of the user is critical in understanding how society interacts, gains value and benefits from the infrastructure. Becker and Vanclay (2003) argue that society can be divided into three groups regarding how infrastructure is experienced.

- The term host community can be applied when a community is situated within close proximity to the physical structure, but does not receive user benefit from the service created. For example, a community situated in close proximity to a railway line, but not within reasonable distance of a train station for which to conduct journeys.

- In contrast, the term source community can be applied to communities that are not located in close proximity to the physical structure, but do benefit from and utilise the service created. An example of this is a community whose waste is 
transported through a sewer system to a waste treatment plant many miles away.

- The third group type proposed by Becker and Vanclay (2003) is a community which is both the host and source. This applies to communities that are impacted by both the physical structure, but also benefit and utilise the service created. Some communities protected by a flood alleviation scheme can be termed both the host and source. This is because they are situated in close proximity to the infrastructure, be it floodwalls, river culverts or floodgates to name but a few. However, they also utilise the service created in the sense that they receive a level of protection from flooding by the scheme.

These different ways in which society can experience infrastructure have limited, to a certain extent, the development of an effective assessment methodology or set of metrics to aid the consideration of this perspective in design and construction. Consequently, the economic and environmental perspectives, which are more quantifiable, tend to take greater precedent.

\section{Emerging Legalisation and Policy}

Emerging UK policy and legislation is beginning to require the articulation and demonstration of the wider value of development, including flood alleviation infrastructure. Both the UK National Infrastructure Plan 2013 (HM Treasury, 2013) and the UK National Planning Policy Framework (NPPF) (Department for Communities and Local Government, 2012) require this articulation and demonstration, but neglect to provide guidance as to how this should be done.

The Public Services (Social Value) Act 2012 became law in the UK in 2012. This focuses upon a socially considered approach to procurement by local authorities and demonstrates the emerging importance of the social perspective in decision-making.

\section{Identification of the Research Gap}

Identifying the social value brought by flood alleviations schemes to communities is important from both the perspective of the communities affected and the requirements of emerging and future legislation. However, the nature of social value means it is highly complex and very subjective and consequently difficult to incorporate in current practice. Rokeach (1979) identifies how the human value system changes over time and is influenced by the different environs that are lived and worked in. Therefore, the social value perceived to be gained by local communities can change over time and can also vary from community member to community member. Downton et al. (2005) echoes this and explains that there is no uniform experience of flood alleviation schemes within communities or society, a 'one size fits all' approach cannot be adopted. This therefore indicates that gaining an understanding of the social value of a scheme is challenging and incorporating this aspect even more 
challenging. In order to be able to consider the social aspect in decisionmaking to a similar extent as the economic and environmental aspects, first an understanding of what is perceived to be the social value of flood alleviation schemes needs to be determined. However, very few methods and approaches exist for this in the context of flood alleviation schemes and this is the area this research seeks to contribute to.

\section{Research Design}

\section{Research Approach}

The approach adopted for this research was qualitative and inductive, following a constructivist grounded theory process. The data was collected through semi-structured interviews with a range of stakeholders, using a real flood alleviation scheme; the Didsbury Flood Storage Basin Improvements scheme. The scheme was chosen for examination using a criteria developed at the outset of the research which included industry commendation. The scheme was commended for its work with the local community during design and construction by the North West branch of the Institution of Civil Engineers (ICE) in 2012.

\section{Scheme Description: Didsbury Flood Storage Basin Improvements}

Didsbury is a suburban area located to the south of the City of Manchester, UK and is under the authority of Manchester City Council (MCC). In the 1970's a flood basin was created in Didsbury as part of a flood management scheme for South Manchester (Environment Agency, 2010). The 62ha basin constructed is used to relieve peak flows on the River Mersey (see Figure 1).

Figure 1. Section of the River Mersey Running through Didsbury

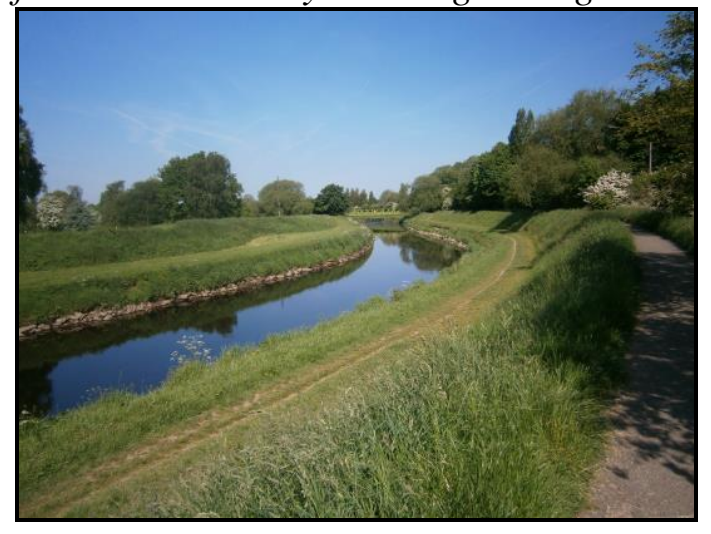

Within the basin, there are two residential properties and a number of local amenities such as recreational land, a rugby club and clubhouse, football club, a golf club and allotments. Under the Reservoirs Act 1975, with additional clarity now provided by the Flood and Water Management Act 2010, the flood basin was not deemed to be operating adequately (Environment Agency, 2010). The body in England responsible for the implementation, management and 
maintenance of flood alleviation infrastructure is the Environment Agency (EA). The EA commenced work on the design of a scheme in 2010 with the aspiration of providing additional protection to the residential properties situated within the flood basin in the form of floodwalls and a flood gate and constructing an additional culvert into the river to ensure the basin can be operated effectively (Collins, 2012). The scheme was completed in December 2011 (Collins, 2012). The scheme protects residential and commercial properties in a suburb called Northenden (Environment Agency, 2010). However, the community of Northenden is not impacted by the physical infrastructure of the scheme and therefore cannot be termed the host community. For this reason, the research focuses on the local community groups and the two residential properties situated within the basin as they can be identified as both the host and source community. The perspectives of groups termed both the host and source were required for this study in order to try to obtain responses concerning social value from participants that both used the service created but could also discuss the construction of the scheme and the impact of the infrastructure.

\section{Data Collection}

The nature of semi-structured interviews allows an exploration of different topics of relevance to the research (Bryman, 2012; Creswell, 2009; Hammersley, 2013). This therefore meant that although there was a discussion guide, depending on the participants, additional topics were explored. In total 18 semi-structured interviews were conducted with 21 participants between April and August 2013. Figure 2 provides an explanation as to how many participants were interviewed and in what capacity.

Figure 2. Number of Participants Interviewed and the Capacity in which they were Interviewed

\begin{tabular}{|c|c|c|c|c|c|}
\hline & \multicolumn{4}{|c|}{ Interview capacity of participants } \\
\hline & & Local community & Local Planning Authority Officer & Design and construction team & Environment Agency Offices \\
\hline \multirow{21}{*}{ 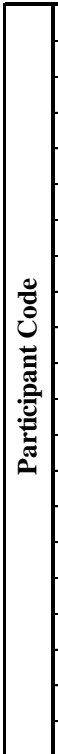 } & 1 & & & & $\mathrm{X}$ \\
\hline & 2 & & & $\mathrm{X}$ & \\
\hline & 3 & & & $\mathrm{X}$ & \\
\hline & $4 \mathrm{a}$ & & & $\mathrm{X}$ & \\
\hline & $4 \mathrm{~b}$ & & & $\mathrm{X}$ & \\
\hline & 5 & & & $\mathrm{X}$ & \\
\hline & 6 & & & & $\mathrm{X}$ \\
\hline & 7 & $\mathrm{X}$ & & & \\
\hline & 8 & $\mathrm{X}$ & & & \\
\hline & 9 & & & & $\mathrm{X}$ \\
\hline & 10 & $\mathrm{X}$ & & & \\
\hline & $11 \mathrm{a}$ & $X$ & & & \\
\hline & $11 \mathrm{~b}$ & $\mathrm{X}$ & & & \\
\hline & 12 & $X$ & & & \\
\hline & 13 & $\mathrm{X}$ & & & \\
\hline & $14 \mathrm{a}$ & $\mathrm{X}$ & & & \\
\hline & $14 \mathrm{~b}$ & $\mathrm{X}$ & & & \\
\hline & 15 & $\mathrm{X}$ & & & \\
\hline & 16 & $\mathrm{X}$ & & & \\
\hline & 17 & & $\mathrm{X}$ & & \\
\hline & 18 & $\mathrm{X}$ & & & \\
\hline
\end{tabular}


Sampling techniques including theoretical sampling (Charmaz, 2006; Urquhart, 2013) and snowball sampling (Bryman, 2012) were employed in order to gather participants. Four types of participants were required for the research to ensure both the local community and those responsible for the design, delivery and construction of the scheme were interviewed. They included:

- Participants classed as local community members, for example those living within the flood basin or spending a lot of recreational time there.

- The local planning authority officer responsible for granting the scheme planning permission.

- The specialists working as part of the design and construction team.

- The Environment Agency officers responsible for the management and delivery of the scheme.

Participants responsible for the design, delivery and construction of the scheme were identified using the documents submitted as part of the planning application (Manchester City Council 2010). Using these documents, key members of the design and construction team were contacted and asked if they would be willing to participate. For local community participants, key amenities within the basin were identified and contact made via available email addresses on their websites explaining the research and the need for participants. For the residents of the basin, contact was made via post. Further participants were gathered by asking at the end of each interview if the current participant could recommend anyone who they believed would be relevant for the research, a technique referred to as snowball sampling. All discussions, apart from three were conducted with individual participants. Three semistructured interviews were conducted with two participants at the same time as requested by the participants themselves. The semi-structured interviews were conducted at convenient locations for the participants, which included local cafes and wine bars, and at the local amenities such as the Rugby Club, Golf Club and allotments. For the participants interviewed in their professional capacity, the discussions were carried out in their place of work. Interviews typically lasted 30-40 minutes and recorded to facilitate transcription. Prior to the interviews, participants received documents which provided a synopsis of the research, information concerning the interview process and ethical use of the data and a signature strip for participants to sign confirming their agreement for the interview to be recorded (see Ryen (2011) for the ethical rationale behind the production of these documents). In addition to the documents discussed, a discussion guide was also sent outlining some of the possible topics for discussion. These topics centered on their understanding of the rationale for the scheme and what was involved, their opinion of the 
scheme and how they interpret the term social value and the social value of the scheme.

Additional sources of secondary data included a review of the planning application (ref: 093534/FO/2010/S2) (Manchester City Council, 2010). This occurred prior to conducting the semi-structured interviews in order to gain a comprehensive understanding of the scheme. Supplementary documents received from both the Environment Agency and the design team were reviewed to help inform the context of the scheme.

\section{Data Analysis}

The data was analysed iteratively in line with the process of constructivist grounded theory (Charmaz, 2006) with the aid of the Computer-Assisted Qualitative Data Analysis Software (CAQDAS) NVivo. The software assisted in managing the large quantities of qualitative data gathered in the form of interview transcripts. The software was also used to code the qualitative data. Open coding was used first to identify key themes within the data and then further coding was conducted to identify relationships among the data and subsequently, the development of theories (Bryman, 2012).

\section{Preliminary Results and Discussion}

The preliminary results presented in this paper focus specifically on participant's responses concerning what is understood by the term social value and how the social value of the Didsbury Flood Storage Basin Improvements scheme was interpreted. The results are presented in three strands: how the term social value was interpreted; how the social value of the scheme was discussed; and where a difference in interpretation exists between the stakeholders interviewed. An examination of these three areas best provides the data from which to begin to develop an understanding of the concept of social value in the context of this research.

\section{Interpreting Social Value}

All 21 participants were hesitant when asked what they understood by the term social value. It was clear from all participant responses, that it was a term not commonly used. This reinforces the argument of Cruz et al. (2009) and Penning-Roswell and Pardow (2012) that the social value of the project is given minimal consideration during both the design and construction process as it was not clearly communicated to the local community.

Once the participants had taken time to consider the term, a range of responses to the question were given. For example, one participant explained,

"Well doing things for the good of the community, doing things that benefit the community." (Interview 8)

Another participant described his understanding of the term as; 
“... social means nothing to do with money, the effects on people's

lives. Value, well again nothing to do with monetary value ... the greatest happiness to the greatest number ..." (Interview 15)

The illustrative quotes above demonstrate the different approaches to the interpretation of the term social value by participants. However, a common theme emerging from the interpretation of the term was that social value was concerned with community wide benefits or value. From the perspective of the participants, social value applied not to individuals but to the benefits and value experienced on a community wide scale. There were no identified differences in the interpretations by the local community and those responsible for the design, delivery and construction of the scheme.

\section{Social Value of the Scheme}

Once participants had articulated their understanding of the term social value, the discussion moved onto how they articulated the social value of the Didsbury Flood Storage Basin Improvements scheme. Figure 3 demonstrates the aspects cited by participants from both the local community and those responsible for the design, delivery and construction of the scheme.

Figure 3. The Aspects of Social Value of the Didsbury Flood Storage Basin Improvements Scheme as Stated by Participants

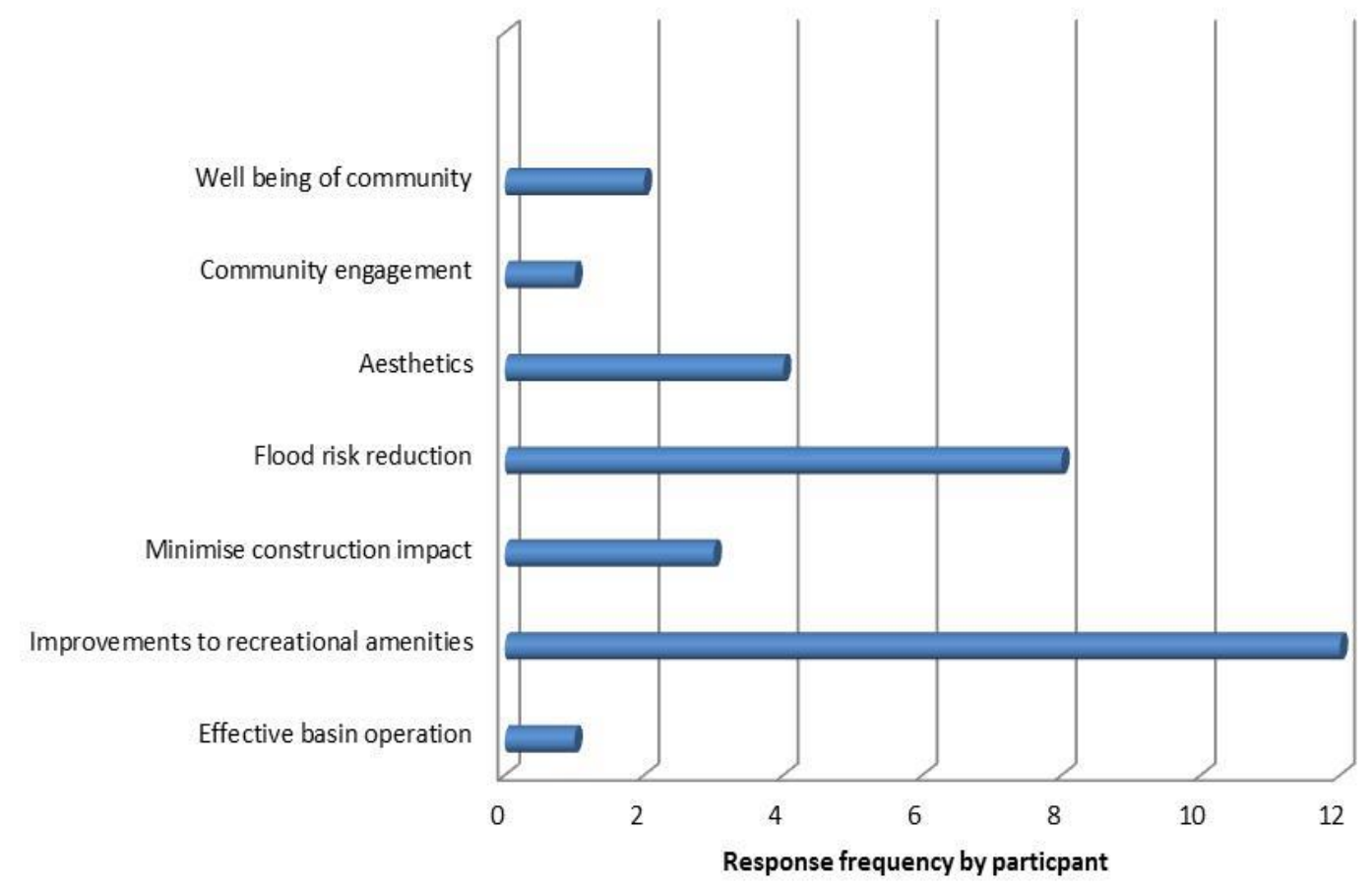

The most cited aspect of social value was the improvements made to the recreational amenities within the basin, cited 12 times. These included environmental enhancements and improvements to local amenities such as a 
local clubhouse. The reduction in flood risk and the protection the scheme affords to residents both within Didsbury and further along the River Mersey was cited eight times, as illustrated by the response of the participant from Interview 15:

"Well obviously one of the benefits to the community is the removal of the risk of having your house flooded ..."

Other attributes cited by participants included; the aesthetics of the final scheme and the achieved minimal impact during the construction process on residents. However, both these attributes were less frequently cited compared to the previous attributes discussed. Effective operation of the basin and what was perceived to be good community engagement were also cited as attributes of the social value of the scheme, but only discussed by one participant per attribute directly. Using Rokeach's (1979) work on how values are created and developed, it is possible to understand why different attributes of social value were cited. The human value system is influenced by the nature of the environment people live and work in. For this reason, what people value differs, resulting in the perceived social value of the scheme differing from participant to participant.

\section{Differences in Interpretation}

In addition to understanding how the term social value was interpreted by participants, the purpose of this paper is also to identify where a difference in interpretation exists between the different groups of participants.

Preliminary analysis of the discussions with participants concerning the general interpretation of the term social value indicates that the interpretation of the term by the local community does not differ from those responsible for the design, delivery and construction of the scheme. Both groups of participants understood social value to be concerned with community wide benefits. However, further analysis identified a difference in how the social value of the scheme was discussed by the local community, compared to those responsible for the design, delivery and construction of the Didsbury Flood Storage Basin Improvements scheme.

Attributes such as protection from flood risk and the aesthetics of design were cited by both the local community and those responsible for the design, delivery and construction as attributes of the social value of the scheme. However, local community participants also cited attributes that were local in context and specific to the area, referring to aspects such as the local clubhouse, allotments, and activities within the wider community. The participants responsible for the design, delivery and construction of the scheme cited attributes that were less context specific and more focused on the design and construction process. One attribute frequently cited by participants interviewed in this capacity was the ability to provide social value through minimal disruption to the local community during the construction process, as illustrated by the following quote: 
"It's within a conservation area, construction traffic was a big issue, we didn't want 30 or 40 trucks trucking up and down quite a small street. There was a church at the top of the road and they were quite often having weddings and funerals and we were working quite closely with them to try and reduce the amount of traffic." (Interview 1)

Another participant echoed this opinion,

"It was really looking to minimise the disruption to recreational activity on the site really and the allotments and the golf course and the rugby club." (Interview 6)

In a similar vein, the disturbance of allotments within the basin was a concern for many residents when plans for the works were prepared. The approach by the design and construction team in order to preserve the allotments and the way of life at the allotments was seen as social value as demonstrated by this participant:

" ... because there is a big community of allotment holders some of them are retired, they would have found it quite distressing if it would have interrupted their natural way of life, it's all right them saying they will be back in a year - what do they do for that year?" (Interview 16)

Although there are similarities in the interpretation of the social value of the Didsbury Flood Storage Basin Improvements scheme, the identification of differences is interesting. The interpretation of the social value of the scheme by those responsible for the design, delivery, and construction focusses on process and their ability to influence and create, what they perceive to be social value. However, local community participants did not frequently interpret the design or construction process as being synonymous with the social value of the scheme. There were more local, context specific attributes cited by the local community participants. A possible explanation for the difference in interpretation could be explained by the work of Becker and Vanclay (2003), Boztepe (2007) and Sandstrom et al. (2008) concerning how infrastructure is experienced. The local community experience the scheme very differently to those responsible for the design, delivery and construction, which results in a different perception of the social value and the benefits gained.

\section{Conclusion}

The consideration of a social perspective in flood alleviation infrastructure design and construction may not be difficult to achieve. This research 
investigated how a local community and those responsible for the delivery, design and construction of a flood alleviation scheme in Manchester, UK interpreted and discussed the social value. This was carried out by conducting 18 semi-structured interviews with 21 participants between April and August 2013.

The preliminary results presented in this paper are part of a wider research project. These results show that the articulation of the concept of social value is similar according to both the local community and those responsible for the design, delivery and construction of the scheme. However, a difference exists in the perceived attributes of the social value of the scheme. Local community members understand the social value to be associated with localised, context specific aspects of the scheme. In comparison, those responsible for the design, delivery and construction of the scheme understand the social value to be associated with the influence they have on the design and construction process. A possible reason for this is because of the way the scheme is used. Local communities experience the infrastructure everyday whereas the design, delivery and construction team only experience the scheme during the time they work on the project, unless the live within the local area. Therefore the perceived social value is very different because the two different groups understand the benefits of the scheme to be different.

The results and discussion presented in this paper have identified how participants of this study articulate social value and the social value of the studied scheme. The ability to understand how social value is interpreted and discussed by the local community and how this interpretation differs compared to those responsible for the design, delivery and construction of the scheme is important. Conducting a similar study on future schemes could equip design, delivery and construction teams with an understanding of how to use similar information during the design and construction stages and seek to employ techniques to enhance the social value where possible. Future work streams could replicate the research design presented here to assess how social value is discussed and interpreted on other flood alleviation schemes. This research has the potential to identify any common themes and any areas of difference regarding social value. Building upon this knowledge, a more long-term direction for future work is the development of an assessment method or tool for use within industry that allows a consistent and transparent approach for the consideration of social value and subsequently the social perspective of flood alleviation schemes.

\section{Acknowledgements}

This research was carried out with the aid of funding from an Engineering and Physical Sciences Research Council (EPSRC) iCase doctoral award. The research is on-going and due for completion in March 2015. The first author would like to thank Dr Maria Christina Georgiadou for her comments on the initial draft of this paper. 


\section{References}

Flood and Water Management Act 2010. (c.29). The Stationery Office: London. Public Services (Social Value) Act 2012. (c.3). The Stationery Office: London. Reservoirs Act 1975. (c.23). The Stationery Office: London.

Becker, H., A and Vanclay, F. 2003: The International Handbook of Social Impact Assessment. Edward Elgar Publishing: Cheltenham.

Boztepe, S. 2007: User Value: Competing Theories and Models. Int. J. Design. 1: 2 (Aug. 2007), 55-63.

Bryman, A. 2012: Social Research Methods. Oxford University Press Inc: New York.

Charmaz, K. 2006: Constructing Grounded Theory: A Practical Guide Through Qualitative Analysis. Sage Publications: London.

Collins, J. 2012. Collaboration at Didsbury Basin. Current. Environment Agency.

Creswell, J. W. 2009: Research Design: Qualitative, Quantitative, and Mixed Methods Approaches. Sage: London.

Cruz, I., Stahel, A. and Max-Neef, M. 2009: Towards a Systemic Development Approach: Building on the Human-Scale Development Paradigm. Eco. Econs. 68 (May 2009), 2021-2030.

Department for Communities and Local Government. 2012. National Planning Policy Framework. DCLG: London.

Downton, M. W., Morss, R. E., Wilhelmi, O. V., Gruntfest, E. and Higgins, M. L. 2005: Interactions Between Scientific Uncertainty and Flood Managment Decisions: Two Case Studies in Colorado. Enviro. Haz. 6:3 (Dec 2008), 134-146.

Environment Agency 2010. Didsbury Flood Storage Basin Improvements: Environmental Report. Bristol.

Frantzeskaki, N. and Loorbach, D. 2010: Towards Governing Infrasystem Transitions: Reinforcing Lock-in or Facilitating Change? Tech. For. \& Soc. Chge. 77:8 (Oct. 2010), 1292-1301.

Geels, F. W. 2007: Transformation of Large Technical Systems: A Multilevel Analysis of the Dutch Highway System (1950-2000). Sci, Tech and Humn. Val. 32;2 (Mar.2007), 123-149.

Germond - Duret, C. 2012: Extractive Industries and the Social Dimension of Sustainable Development: Reflection on the Chad-Cameroon Pipeline. Sustainable Development. DOI: 10.1002/sd.1527

Hammersley, M. 2013: What is Qualitative Research? Bloomsbury: London.

HM Treasury 2013. National Infrastructure Plan. HM Treasury: London.

Hughes, T. P. 1983: Networks of Power: Electrification in Western Society, 18801930. Johns Hopkins University Press: Baltimore.

IPCC 2013. Working Group I Contribution to the IPCC Fifth Assessment Report Climate Change 2013: The Physical Science Basis Summary for Policymakers [Online]. Available: http://www.ipcc.ch/ [Accessed 01/04/2014.

Johannessen, A. and Hahn, T. 2013: Social learning towards a more adaptive paradigm? Reducing flood risk in Kristianstad municipality, Sweden. Glo. Enviro. Chnge. 23 (Feb. 2013), 372-381.

Jonsson, D. 2000: Sustainable Infrasystem Synergies: A Conceptual Framework. J. Urb. Tech. 7, 81-104.

Jonsson, D. 2005: The Nature of Infrasystem Services. J. Infrastruct. Syst. 11 (Mar. 2005), 2-8. 
Manchester City Council. 2010. Public Access [Online]. Available: http://pa.manches ter.gov.uk/online-applications/simpleSearchResults.do;jsessionid=CD4283E931 B739FB0F45159AEDBABA56?action=firstPage [Accessed 03/03/2014.

Markard, J. 2011: Transformation of Infrastructures: Sector Characteristics and Implications for Fundamental Change. J. Infrastruct. Systs. 17:3 (Mar 2011), 107-117.

Marshall, T. 2012: Planning Major Infrastructure: A Critical Analysis. Routledge: Oxon.

Penning-Roswell, E., C., and Pardow, J. 2012: Who benefits and who loses from flood risk reduction? Enviro. Plan. C: Govment. Pol. 30:3, 448-466.

Rokeach, M. 1979. Understanding Human Values: Individual and Societal. In: Rokeach, Milton. (ed.). Collier Macmillan Publishers: London.

Ryen, A. 2011. Ethics and Qualitative Research. In: Silverman, D. (ed.) Qualitative Research. 3rd ed. Sage: London.

Sandstrom, S., Edvardsson, B., Kristensson, P. and Magnusson, P. 2008: Value in Use through Service Experience. Manging. Ser. Qual. 18:2, 112-116.

Simm, J. D. 2012: A Framework for Valuing the Human Dimensions of Engineered Systems. Proceedings of the ICE - Engineering Sustainability. 165, 175-189.

Star, S. L. 1999: The Ethnography of Infrastructure. A. Behv. Scist. 43:3 (Nov. 1999), 377-391.

Tripathi, R., Sengupta, S. K., Patra, A., Chang, H. and Wong, I. W. 2014: Climate change, urban development, and community perception of an extreme flood: A case study of Vernonia, Oregon, USA. App. Geog. 46 (Jan. 2014), 137-146.

Urquhart, C. 2013: Grounded Theory for Qualitative Research: A Practical Guide. Sage: London.

Van der Vleuten, E. 2004: Infrastructure and Societal Change. A View from the Large Technical Systems Field. Tech. Anal. Strategic. Manage. 16;3, 395-414. 